\title{
IDENTIFICATION OF ATTRIBUTES OF INFORMATION AS AN ELEMENT OF MANAGEMENT SECURITY OF INFORMATION IN THE COMPANY
}

doi: 10.2478/cqpi-2019-0023

Date of submission of the article to the Editor: 25/03/2019

Date of acceptance of the article by the Editor: 17/05/2019

\author{
Żywiołek Justyna ${ }^{1}$ - orcid id: 0000-0003-0407-0826 \\ Nedeliaková Eva ${ }^{2}$ - orcid id: 0000-0001-5588-0939 \\ ${ }^{1}$ Częstochowa University of Technology, Poland \\ ${ }^{2}$ University of Žilina, Slovakia
}

\begin{abstract}
Information is a special type of resource in an enterprise. is an indispensable element of every action taken. The article presents the essence of resources subject to special protection, affecting the company's information security. This allowed to identify the information attributes in the area of security of the surveyed enterprises. The article analyzes the attributes of information affecting the activities of the surveyed enterprises, the pace of work, information chaos. The research confirmed the importance of the information features, which will help the employer and superiors to evaluate the manner, frequency of providing information and making a screening to whom the information is provided.
\end{abstract}

Keywords: information security, information attributes, data processing in the enterprise

\section{INTRODUCTION}

The rapid progress in the technological and IT area observed since the turn of the 20th and 21 st centuries, mainly in the field of mobile technologies and ICT, has had a significant impact on all spheres of human life. Dynamic development of communication media, as well as the increasing availability of electronic devices enabling the use of the Internet, have contributed to the easy acquisition of information being currently one of the most important strategic resources of modern states and organizations.

Due to the constantly growing importance and importance of information, which is a factor of advantage among enterprises, and even often decisive for their safety. More and more attention is paid to the issues of information security, protection of information systems and safe processing of data contained in them. This issue seems to be important because today almost every company is becoming more and more dependent on the safe flow of information and failure-free operation of systems based on extensive information resources. Ensuring information security is, however, a very complex undertaking, and its success depends on many factors, including the skillful 
management of information security, the development of a number of organizational and technical procedures, and finally - the level of awareness of people allowed to process information.

\section{INFORMATION ATTRIBUTES}

The concept of information security, according to the literature of the subject is defined as a set of undertakings aimed at protecting information, an important element of the modern economic system, which is an institution or economic organization ensuring its effective and reliable functioning (Axelrod, Bayuk, Schutzer, 2009). According to the content presented in the literature, information is considered safe when all the attributes of its security are guaranteed:

confidentiality, integrity, availability, accountability, authenticity, non-reputation and reliability (Tallinn, Castelfranchi, Falcone, Marzo, 2010). Therefore, security information should be multidimensional, taking into account not only the multiplicity of information attributes to be protected (Brzozowska, 2015), but also the diversity of their forms. The characteristics of individual security attributes are approximated in Figure 1.

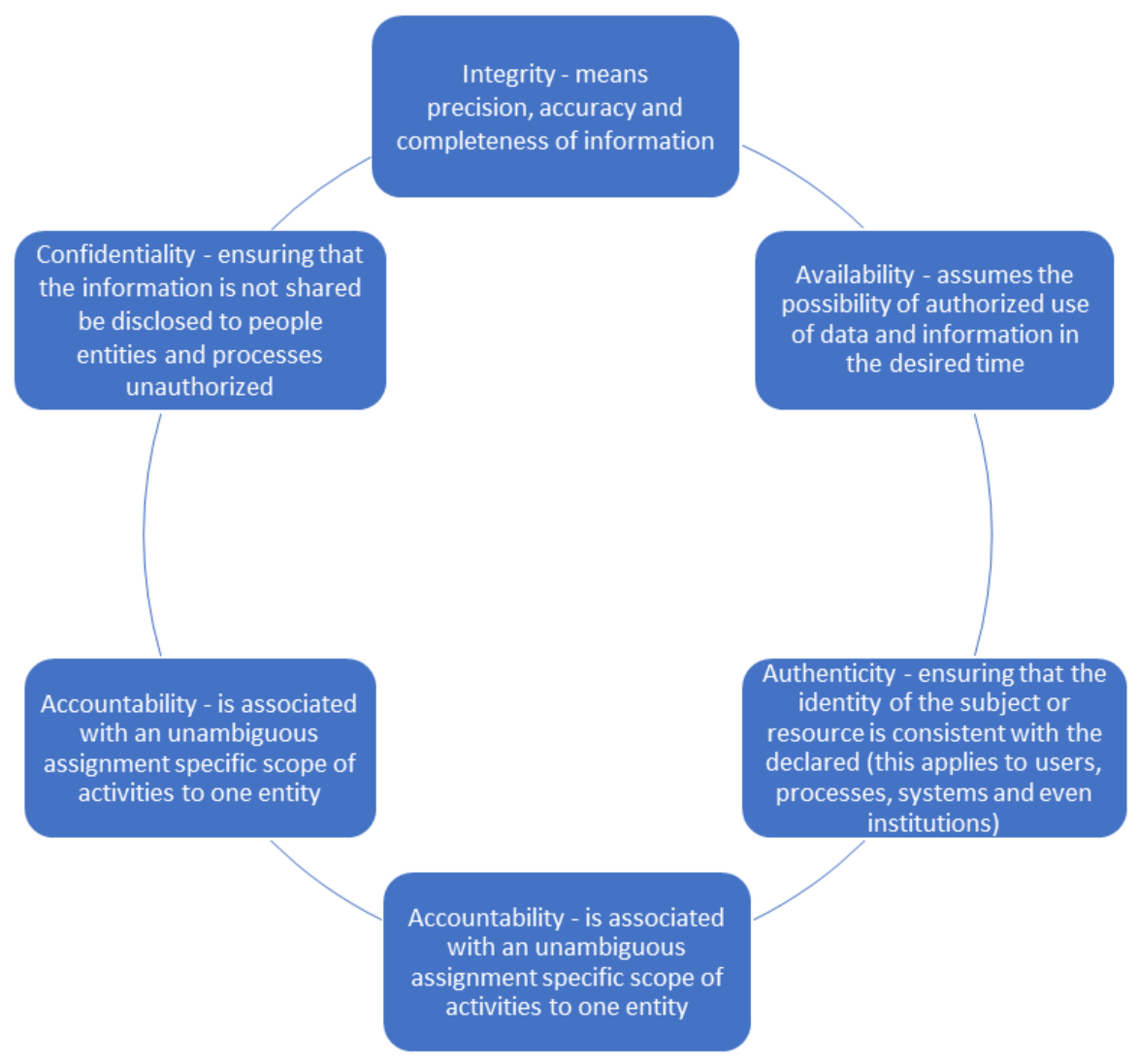

Fig. 1. Information security attributes

The issue of information security in today's world applies to virtually all enterprises. A survey of information artifacts was conducted in the surveyed company.

\section{EMPLOYEES' AWARENESS OF INFORMATION ATTRIBUTES}

For the study of information features in enterprises that implement information security, a questionnaire was carried out, which included employees of middle and senior 
management as well as management or owner of the enterprise. The questionnaire contained 30 questions in a large number of cheats or multiple selections. Before starting an anonymous questionnaire, the employees participated in the training on information security awareness, where they were indicated what attributes of information constitute their individual characteristics, which influences the safe security foundations in enterprises. IT specialists, managerial staff, safety manager, board plenipotentiary participate in the survey. Employees of three large manufacturing companies participate in the survey. Thanks to this research, the level of employees' awareness in the field of information security has been evaluated by specifying the attributes of the information they have. Element of the employee awareness assessment was the determination of the requirements that should be placed on the information security system (Pawełoszek, 2014). It must first and foremost enable the basic factors affecting its functioning, including ensuring confidentiality, integrity, accessibility, accountability, authenticity and reliability.

a
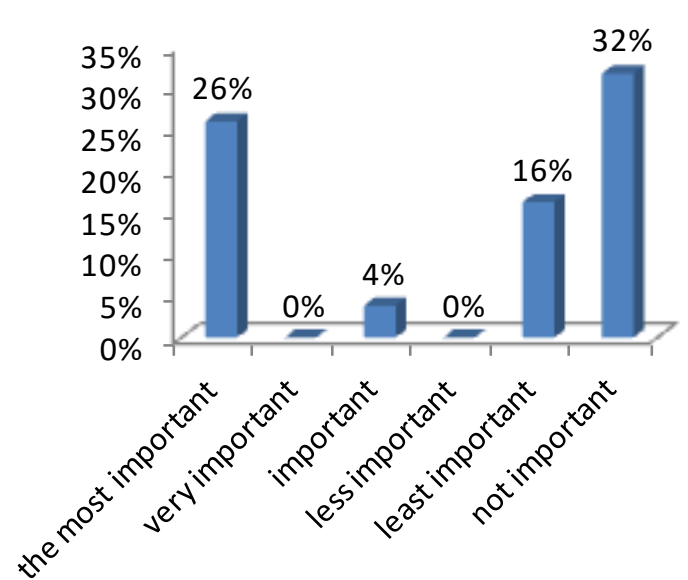

\section{accessibility}

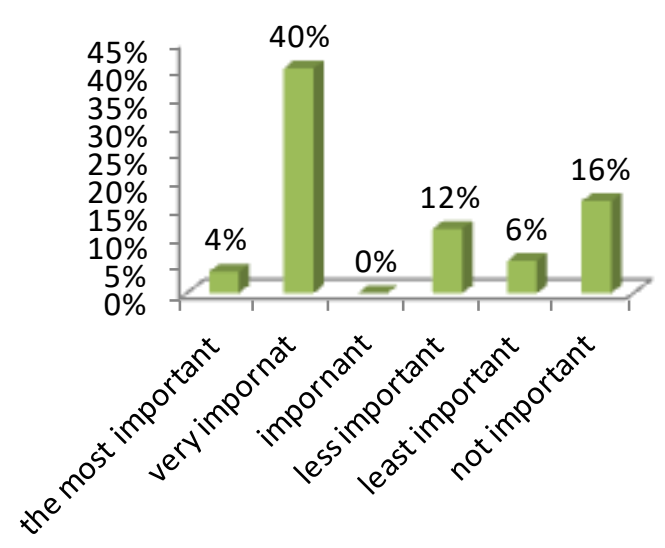

integrity

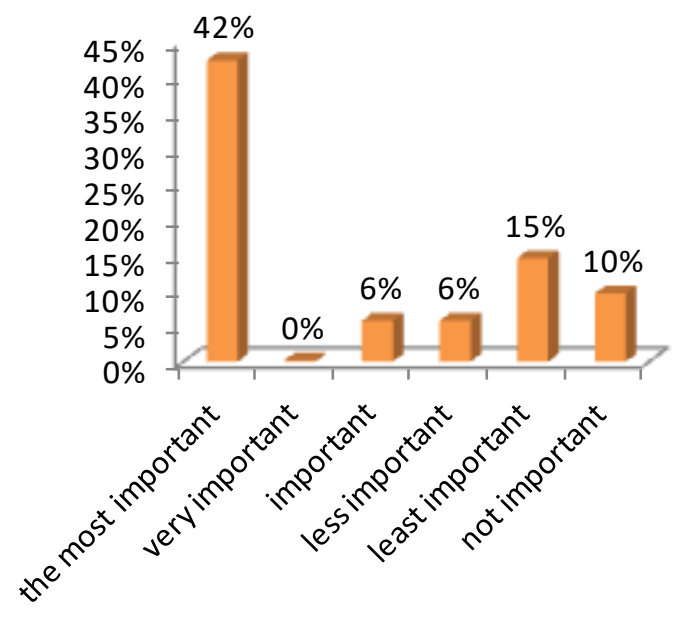

accountability
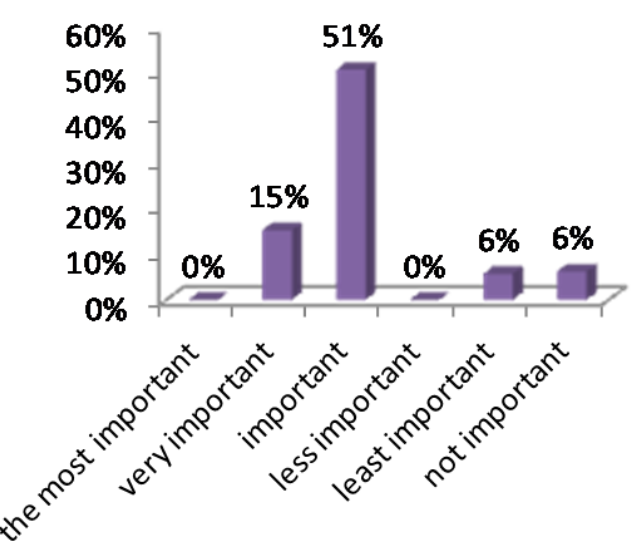


\section{authenticity}
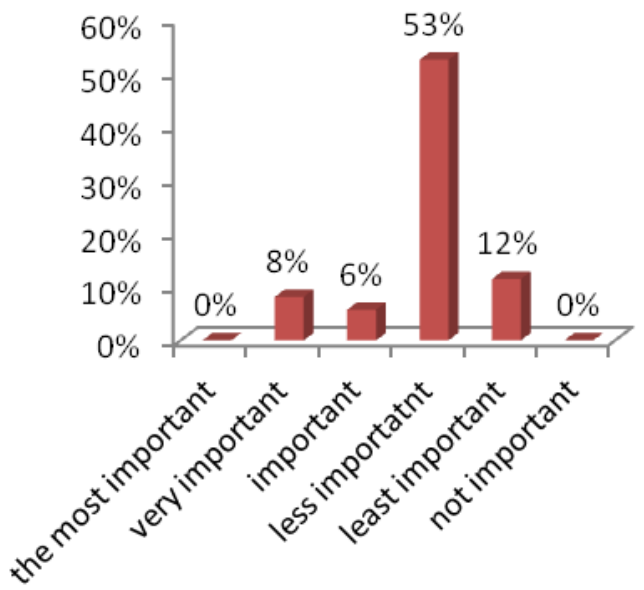

reliability
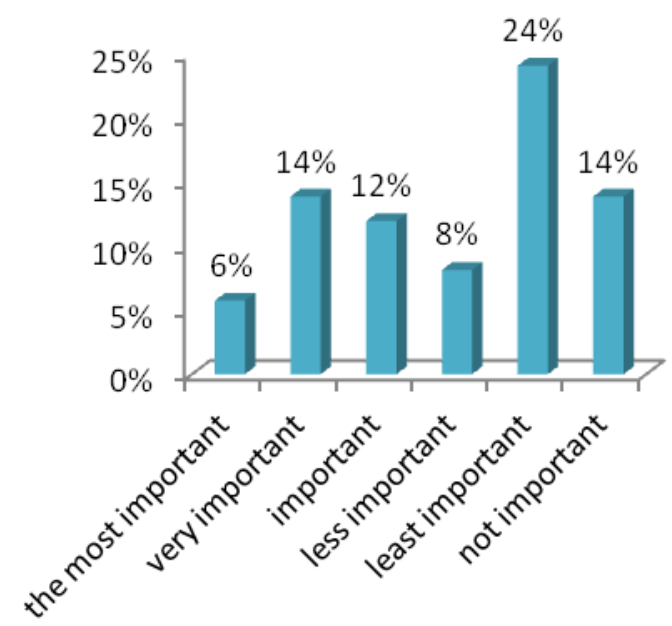

Fig. 2. Requirements for ensuring by the information security system

The requirements for an information security system are attributes of information. When reviewing statutory documents, standards (PN, EN, ISO / IEC), allied standards and business and association recommendations related to information protection, one can find a description from several to a dozen attributes assigned to the concept of "information" (Bubel, 2015), depending on the indicated (specified in a given document) of the anticipated environment for the protection of these attributes (Grodzki, Piech, 2017). Characteristic for the description of information are primarily: confidentiality, integrity, availability, accountability, authenticity, reliability (Zou, Lun, Cipolla, Mohamed, 2017).

In each case, the information security assessment is based on the ability to ensure, achieve and maintain at the set level all of its defined attributes (it is extremely important in this case to refer to incident events that threaten the information itself which broadly identifies the ISO / IEC TR 18044 Security Incident Management protocol ) (Brandis, 2016).

Information security management is only possible in a specific and limited area covered by an information system including information, media, devices and information users. A properly constructed information system should, regardless of the form (direct / recording on the carrier) and the nature of information (explicit, protected / secret) meet three basic criteria: ensuring information security, ensuring the safety of service provision, ensuring the authenticity and accountability of data and entities (Durodolu, 2016).

To create an information system based on the described criteria, you can use the experience and knowledge of the company's employees to conduct (Żywiołek, 2018):

- risk analysis and assessment of the degree and level of risk occurring for information,

- constructing an information security policy that interprets the principles of information management in this system,

- implementation of methods and methods eliminating susceptibility to anticipated and probable threats of both the information itself and the media containing it. 
The relationship between the answer regarding the importance of individual elements of the security system in the company and the responses provided by manual workers (Fig. 3) or white-collar workers was also examined (Fig. 4).
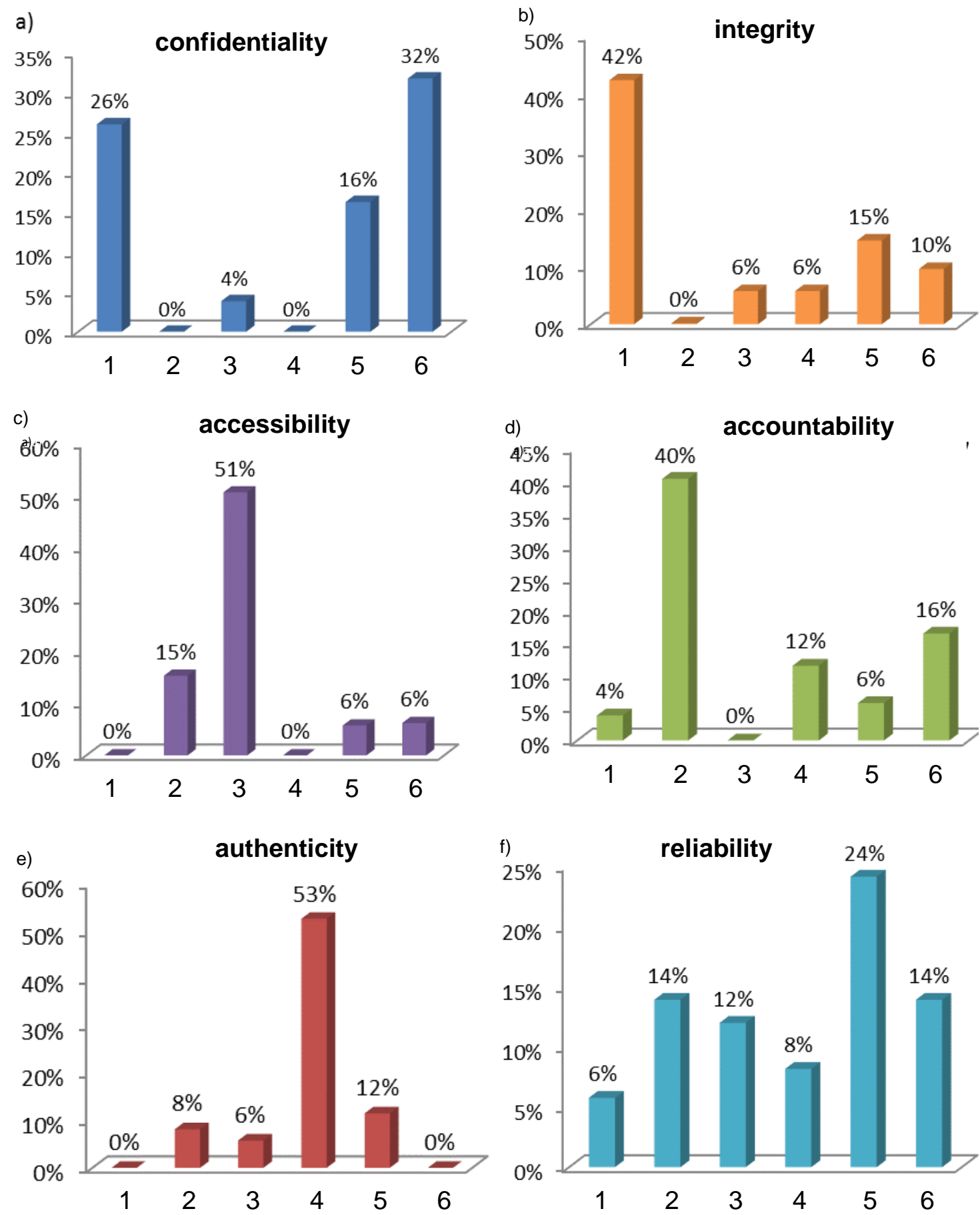
1 The most important
2 Very important
3 Important
4 Less important
5 Least important
6 Not important

Fig. 3. Evaluation of the company's security system by manual workers 

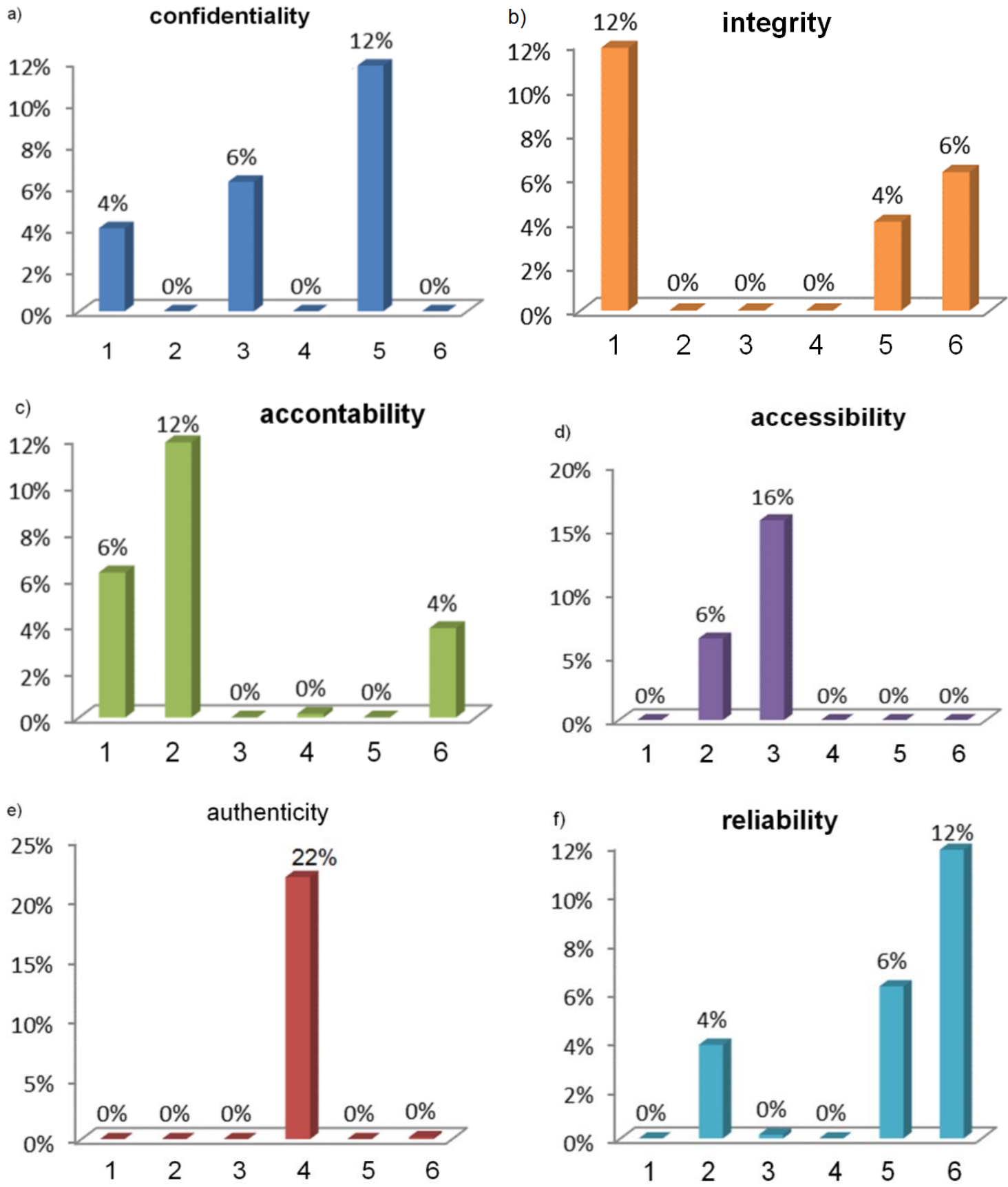

$\begin{array}{ll}1 & \text { The most important } \\ 2 & \text { Very important } \\ 3 & \text { Important } \\ 4 & \text { Less important } \\ 5 & \text { Least important } \\ 6 & \text { Not important }\end{array}$

Fig. 4. Evaluation of the enterprise security system by white-collar workers

Physical workers paid the most attention to the integrity of the data, i.e. the need to be sure that the information was not changed or deleted by unauthorized persons. The physical workers feel responsible for the melting and its quality, and without the actual information about the melting, finished products could not be made. Another element 
that was highlighted by manual workers was the availability of information, which states that only authorized persons can use it at a given place and time. The confidentiality of information is an element that has been considered the least important, i.e. an information security function providing access or lack of access. Physical workers are not fully aware that information is a good that, for example, used by competitors can become a threat to the enterprise.

Also, white-collar workers assessed the company's security system. according to them, the integrity and availability of information are the most important elements. The diversity of responses was greater than that of manual workers due to the diversity of positions of the employees surveyed. The reliability of information has been considered the least important, ie the certainty that the information will reach the recipient. Mental workers took it for granted that the necessary information for work would be provided.

\section{CONCLUSION}

Attributes of information are strictly defined and allow to give specific features to information. Without one of the attributes, the information will hit the values and their total absence allows to state that the information is worthless. Conducted research among production and mental workers, it can be concluded that various employee groups pay attention to various attributes of information, while production workers only need information that is current and available. Only mind workers attach more importance to other traits. The conducted analysis is the basis for further research in the area of information security in the enterprise.

Research carried out earlier by the author proved the legitimacy of monitoring behavior regarding information, information overload and even information chaos. However, only by providing access to information, we can examine the features of the information they have, so it is easier for employees to assess whether they are reliable if they are strictly related to his work, accessible or easily obtainable. Employees specifying the importance of traits give employers an indication of how to provide employees with information on the frequency in order to improve their work and not to hinder it with information chaos.

\section{REFERENCE}

Axelrod, C.W., Bayuk, J.L., Schutzer D. (eds.), 2009, Enterprise Information, Security and Privacy, Artech House, Norwood.

Brandis K. et. al., 2016, A process framework for information security management "International Jurnal of Information Systems and Project Management", Vol 4, No 4.

Durodolu, O., 2016, Technology Acceptance Model as a predictor of using information system' to acquire information literacy skills "Library Philosophy and Practice", November.

Grodzki G., Piech H., 2017, Audit Expert System of Communication Security Assessment, Procedia Computer Science.

Pawełoszek I., 2014, Semantic Organization of Information Resources for Supporting the Work of Academic Staff, Annals of Computer Science and Information Systems.

Tallinn. Castelfranchi C., Falcone R., Marzo F., 2010, Trust and relational capital "Computational and Mathematical Organization Theory", Vol 17, Issue 2, 2016. 
Zou P., Lun P., Cipolla D., Mohamed S., Safety Science, 98 (2017), Available at: https://www.sciencedirect.com/science/article/pii/S0926580517309561 [Accessed 14 Apr. 2019].

Żywiołek J., 2018, Monitoring of Information Security System Elements in the Metallurgical Enterprises, MATEC Web of Conferences, https://www.matecconferences.org/articles/matecconf/pdf/2018/42/matecconf_qpi2018_01007.pdf.

Syreyshchikova N., Pimenova D., Mikolajczyk T., Moldovan L., 2019, Information Safety Process Development According to ISO 27001 for an Industrial Enterprise, Procedia Manufacturing 32.

Bubel D., 2015, Analysis of Information Systems in the Aspect of Managing Logistic Processes of Supply Chain, Springer, Cham.

Brzozowska A, Bubel D, Pabian A., 2015, Implementation of Technical and Information Systems in Environmental Management, Procedia - Social and Behavioral Sciences, Vol.213. 